\title{
Rapid reduction of maternal mortality in Uganda and Zambia through the saving mothers, giving life initiative: results of year 1 evaluation
}

Florina Serbanescu ${ }^{1,7,8^{*}}$ D. Howard I. Goldberg ${ }^{1}$, Isabella Danel ${ }^{1}$, Tadesse Wuhib ${ }^{2,7}$, Lawrence Marum ${ }^{3,7}$, Walter Obiero ${ }^{2,7}$, James McAuley ${ }^{3,7}$, Jane Aceng ${ }^{4}$, Ewlyn Chomba ${ }^{5}$, Paul W. Stupp ${ }^{1,7}$ and Claudia Morrissey Conlon ${ }^{6,7}$

\begin{abstract}
Background: Achieving maternal mortality reduction as a development goal remains a major challenge in most low-resource countries. Saving Mothers, Giving Life (SMGL) is a multi-partner initiative designed to reduce maternal mortality rapidly in high mortality settings through community and facility evidence-based interventions and district-wide health systems strengthening that could reduce delays to appropriate obstetric care.

Methods: An evaluation employing multiple studies and data collection methods was used to compare baseline maternal outcomes to those during Year 1 in SMGL pilot districts in Uganda and Zambia. Studies include health facility assessments, pregnancy outcome monitoring, enhanced maternal mortality detection in facilities, and population-based investigation of community maternal deaths. Population-based evaluation used standard approaches and comparable indicators to measure outcome and impact, and to allow comparison of the SMGL implementation in unique country contexts.
\end{abstract}

Results: The evaluation found a 30\% reduction in the population-based maternal mortality ratio (MMR) in Uganda during Year 1, from 452 to 316 per 100,000 live births. The MMR in health facilities declined by 35\% in each country (from 534 to 345 in Uganda and from 310 to 202 in Zambia). The institutional delivery rate increased by 62\% in Uganda and 35\% in Zambia. The number of facilities providing emergency obstetric and newborn care (EmONC) rose from 10 to 25 in Uganda and from 7 to 11 in Zambia. Partial EmONC care became available in many more low and mid-level facilities. Cesarean section rates for all births increased by 23\% in Uganda and 15\% in Zambia. The proportion of women with childbirth complications delivered in EmONC facilities rose by 25\% in Uganda and 23\% in Zambia. Facility case fatality rates fell from 2.6 to $2.0 \%$ in Uganda and 3.1 to $2.0 \%$ in Zambia.

Conclusions: Maternal mortality ratios fell significantly in one year in Uganda and Zambia following the introduction of the SMGL model. This model employed a comprehensive district system strengthening approach. The lessons learned from SMGL can inform policymakers and program managers in other low and middle income settings where similar approaches could be utilized to rapidly reduce preventable maternal deaths.

Keywords: Maternal mortality, Pregnancy complications, Emergency obstetric care, Verbal autopsy, Low-resource countries, Sub-Saharan Africa

\footnotetext{
* Correspondence: fserbanescu@cdc.gov

${ }^{1}$ Division of Reproductive Health, Centers for Disease Control and Prevention,

4770 Buford Hwy, Atlanta, GA 30341, USA

${ }^{7}$ Saving Mothers Giving Life Research Group, Atlanta, USA

Full list of author information is available at the end of the article
} 


\section{Background}

Maternal mortality remains high in sub-Saharan Africa (SSA) despite recent efforts to accelerate reduction [1-3]. The maternal mortality ratio (MMR) in SSA is estimated to have declined by $49 \%$ since 1990 , however, at 510 maternal deaths per 100,000 live births, remains the highest regional maternal mortality of the world. It is almost three times higher than in Southern Asia and 30 times higher than in high-resource regions $[4,5]$. The great majority of maternal deaths are preventable through effective, lowcost interventions [6-11].

Saving Mothers, Giving Life (SMGL) is a multi-partner initiative designed to rapidly reduce deaths stemming from pregnancy and childbirth through a comprehensive set of evidence-based interventions in high-mortality, low-resource settings. It established an ambitious target of a $50 \%$ decline in the MMR in one year to address the need for accelerated progress to meet the fifth Millennium Development Goal (MDG5) of a 75\% reduction in MMR by 2015 .

SMGL draws upon the investment and expertise of public and private organizations and existing infrastructure, partnerships, and services, including US Government platforms for combating HIV/AIDS and improving maternal and child health $[12,13]$. SMGL is based on a health district-strengthening model that is planned and carried out in close collaboration with the national Governments of Uganda and Zambia and with local governments in SMGL districts. Other current partners are the US Government [Centers for Disease Control and Prevention (CDC), US Agency for International Development (USAID), US Peace Corps, US Department of Defense, and US Office of the Global AIDS Coordinator], the American College of Obstetricians and Gynecologists, Every Mother Counts, Merck for Mothers, the Government of Norway, and Project CURE.

The SMGL model aims for rapidly achievable, measurable, sustainable reductions in maternal and newborn mortality and Prevention of Maternal to Child Transmission of HIV. It employs a comprehensive approach that strengthens district health systems to ensure that every pregnant woman has access to safe basic delivery services and, in the event of an obstetric complication, life-saving emergency obstetric and newborn care (EmONC) [14] within $2 \mathrm{~h}$. The model builds upon existing district health strategies and platforms to address the "Three Delays", i.e., delays in: seeking appropriate services; reaching those services; and receiving timely, quality care at the facility [15]. It promotes and closely monitors evidence-based interventions in facilities around the time of labor, delivery and immediately postpartum, [16-20] when earlier studies estimate that most maternal deaths and about half of newborn deaths occur [21-26]. In collaboration with the governments of Uganda and Zambia, SMGL has introduced in 2012 a wide range of interventions in communities and health facilities (public and private) in 4 pilot districts in each country. These included: a) demand generation for antenatal, facility delivery, postpartum care and raising awareness about birth planning, pregnancy complications, HIV testing and treatment and postpartum family planning services; b) facility upgrading and equipping, provisions of medical commodities and supplies including safe blood, and hiring, training and mentoring mid and high level staffing to increase the number and geographical distribution of quality basic and comprehensive EmONC services with $24 \mathrm{~h}$ coverage; c) strengthening linkages between communities and facilities through integrated communications and transportation systems and opening of new maternity waiting homes; and d) increasing capacity of district health office personnel and facility personnel for data collection, management and use and thus strengthening host country health management information systems (Table 1).

The SMGL districts in Uganda and Zambia differ in many important ways (Table 2) [27, 28]. Ugandan districts have more hospitals and health centers with surgical capacity, including a regional hospital that covers 7 districts. In both countries, most hospitals are designated to perform comprehensive obstetric care, including surgeries. Health centers are generally designed to provide basic emergency obstetric care. Health posts provide routine delivery care and refer complicated births to higher level facilities. District-wide facility and community SMGL activities were geared toward increasing access to and availability of quality obstetric care (Table 3) [29, 30].

This paper provides key results for Year 1 of the SMGL initiative that serve as "proof of concept" and as the basis for scale-up in Uganda, Zambia and potentially additional countries. The focus is on maternal mortality reduction and its principal determinants. Details of process-related results are reported elsewhere [29].

\section{Methods}

SMGL used multiple monitoring and evaluation processes with varied data sources (Table 4). Comparisons of maternal and perinatal outcomes were made between a baseline period (June 2011-May 2012) and Year 1 (June 2012-May 2013) after full implementation of SMGL interventions. Key indicators compared include: EmONC process and outcome monitoring indicators, [14] maternal mortality ratios in facilities in both countries, as well as population-based maternal mortality measurements in Uganda [31].

Overall and cause-specific maternal mortality were calculated after classifying identified deaths using the World Health Organization (WHO)'s maternal mortality application of the ICD-10 (ICD-MM) [32]. We 
Table 1 SMGL Interventions Implemented in Uganda and Zambia to reduce the Three Delays

Increase Awareness and Seeking Care for Safe Delivery (to reduce the First Delay)

- Training of Village Health Teams to encourage birth preparedness and increase demand for facility-based delivery care

- Community outreach activities to counsel women, families, local leaders, and community organizations on the importance of birth planning, recognition of danger signs of pregnancy complications, attending at least 4 antenatal care visits, facility delivery care, HIV testing and treatment, post-partum homecare for mother/newborn and postpartum family planning.

- Distribution of Mama Kits to incentivize facility-based births

- Community mobilization messages (radio, billboards, newspaper articles) and drama skits

- Promotion of demand- and supply-side financial incentives to facilitate women seeking, accessing and utilizing quality care services (eg. transport and delivery care vouchers, user-fee reductions, and conditional cash transfers).

Increase access to quality health care services (to reduce the Second Delay)

- Upgrade a sufficient number of public and private facilities with appropriate geographical positioning to provide $-24 \mathrm{~h}$ per day $/ 7$ days a week - clean and safe basic delivery services, quality HIV testing, counseling and treatment (for woman, partner, and baby as appropriate), and essential newborn care for all pregnant women in the district.

- Ensure that a minimum of five emergency obstetric and newborn care (EmONC) facilities (public and private), including at least one facility that can provide comprehensive EmONC per 500,000 population are providing the recommended life-saving obstetric interventions $24 \mathrm{~h}$ per day/7 days a week.

- Hire a sufficient number ${ }^{a}$ of skilled birth attendants to provide, on a consistent basis, quality respectful basic delivery care, diagnosis and stabilization of complications, and if needed, timely facilitated referral for EmONC. Performance-based EmONC-trained personnel in facilities that provide basic and comprehensive EmONC.

- Create a 24-h/7 day per week, consultative, protocol-driven, quality-assured, integrated (public and private) communication/ transportation referral system that ensures women with complications reach emergency services within $2 \mathrm{~h}$. This includes providing, where appropriate, temporary lodging in maternity waiting homes for women with high-risk pregnancies or who live greater than 2-h travel time to an EmONC facility.

Improve quality, appropriate and respectful care (to reduce the Third Delay)

- Train health professionals in emergency obstetric care, including obstetric surgeries

- Ensure mentoring of newly hired personnel and supported supervision

-Strengthen supply chains for essential supplies and medicines

- Ensure implementation of quality, effective interventions to prevent and treat obstetric complications (MgSO4, infection prevention practices, assisted vaginal delivery, Active Management of the Third Stage of Labor [AMSTL], C-section and other obstetric surgeries (e.g., laparotomy, hysterectomy, repairs following obstetric complications), safe blood supplies, prevention of HIV maternal to child transmission, etc.)

- Introduce sound managerial practices utilizing 'short-loop' data feedback and response, to ensure reliable delivery of quality essential and emergency maternal and newborn care.

- Strengthen maternal mortality surveillance in communities and facilities, including timely, no-fault, medical death reviews performed in follow-up to every institutional maternal death with cause of death information used for ongoing monitoring and quality improvement.
Table 1 SMGL Interventions Implemented in Uganda and Zambia to reduce the Three Delays (Continued)

- Promote a government-owned HMIS data-gathering system that accurately records every birth, obstetric and newborn complication and treatment provided, and birth outcomes at public and private facilities in the district. Where appropriate, $\mathrm{m}$-health approaches to facilitate the monitoring activities.

${ }^{\mathrm{a} W H O}$ guidelines recommend 1 midwife per 120 deliveries/year; 1-2 doctors and 6 medical personnel (midwives, clinical officers, and nurses) for every 1000 births.

calculated MMRs in facilities in both countries (using the number of live births in facilities as the denominator) and population-based MMR in Uganda (using the estimated number of live births in the SMGL districts).

A brief overview of the data sources is presented below:

\section{Health facility assessments (HFA)}

Each country conducted a baseline and Year 1 HFA of every facility that provided delivery care in the SMGL districts, whether public, private, or faith-based, using a modified version of the standard point-in-time EmONC questionnaire [33]. Baseline data were collected by trained personnel several months prior to SMGL implementation (January 2012 in Zambia and March 2012 in Uganda). These data were used to assess current facility capacity to perform life-saving EmONC interventions [29]. The assessment of all delivering facilities in all districts allowed for a rational distribution of human and financial resources to strengthen the safe-delivery network through infrastructure upgrades and capacity building during the first year. The Year 1 HFAs conducted in July-August 2013 were used to assess infrastructure and capacity at the end of Year 1.

\section{Pregnancy outcome monitoring in facilities}

Individual and aggregate retrospective pregnancy outcome data, including facility maternal deaths, were collected from delivering facilities by trained health staff and evaluation personnel. In Uganda, staff collected individual data on maternal, delivery-including obstetric surgeries-and newborn outcomes in facilities with comprehensive EmONC (CEmONC) [34]. They collected information on up to three maternal complications at the time of delivery, but only the most immediately life-threatening complication was used to analyze maternal morbidities and direct obstetric case fatality rates (CFR). Only aggregated reporting using specially designed extraction forms was employed in lower level facilities in Uganda and all facilities in Zambia, primarily from maternity registers. Surgical and admission/discharge registers were used in higher level facilities. Two districts in Zambia used broader aggregation of obstetric complications that precluded a separate 
Table 2 Selected national and SMGL Districts Indicators before Interventions

\begin{tabular}{|c|c|c|}
\hline Characteristic & Uganda & Zambia \\
\hline \multicolumn{3}{|l|}{ National Indicators } \\
\hline Life expectancy at birth (male/female) $(2012)^{a}$ & $56 / 58$ & $55 / 58$ \\
\hline \multicolumn{3}{|l|}{ Health Expenditures } \\
\hline Total expenditure on health as \% of GDP (2011) $)^{a}$ & 9.3 & 6.2 \\
\hline Total expenditure on health as \% of general government expenditures ${ }^{a}$ & 10.1 & 16.4 \\
\hline \multicolumn{3}{|l|}{ SMGL 4-District Indicators } \\
\hline Area (sq. km) & 10,851 & 49,468 \\
\hline Population $(2011)^{\mathrm{b}}$ & $1,750,000$ & 925,198 \\
\hline$\%$ of Population in rural areas & $84 \%$ & $61 \%$ \\
\hline Women of Reproductive Age ${ }^{b}$ & 342,060 & 193,515 \\
\hline Expected Live Births ${ }^{c}$ & 78,261 & 37,267 \\
\hline \multicolumn{3}{|l|}{ Type of Health Care Facility ${ }^{d}$} \\
\hline Health Posts & 19 & 16 \\
\hline Health centers without surgical care & 72 & 91 \\
\hline Health centers with surgical care & 8 & 0 \\
\hline District Hospitals & 7 & 6 \\
\hline Regional Hospital $^{e}$ & 1 & 0 \\
\hline \multicolumn{3}{|l|}{ Facility Ownership ${ }^{f}$} \\
\hline Government & 65 & 106 \\
\hline Private for profit & 11 & 0 \\
\hline Private not for profit & 31 & 7 \\
\hline \multicolumn{3}{|l|}{ Emergency Obstetric and Newborn Care (EmONC) Facilities ${ }^{f}$} \\
\hline Comprehensive EmONC & 7 & 4 \\
\hline Basic EmONC & 3 & 3 \\
\hline
\end{tabular}

${ }^{\mathrm{a}}$ GDP Gross Domestic Product. Source: World Health Statistics, 2014

${ }^{b}$ Based on the district-wide census of the population conducted in 2013 in Uganda (4 districts) and in 2012 in Zambia (4 districts) and projected back to 2011 [31] ${ }^{\mathrm{C}}$ Estimated by summing the expected births in each age group (number of women of reproductive age from district-wide census multiplied by their age specific fertility rates from 2011 DHS) in Uganda and by applying 2010 Census crude birth rates in Zambia

${ }^{\mathrm{d}}$ Health facilities providing delivery care prior to SMGL [29]

${ }^{\mathrm{e}}$ Fort Portal is the regional referral hospital located in Kabarole district; it has 351 beds and serves the entire Ruwenzori region constituted of 3 SMGL-supported districts (Kabarole, Kyenjojo, Kamwenge) and 4 non-SMGL districts (Kasese, Ntoroko, Kyegegwa and Bundibujyo)

fEmONC includes a set of life-saving interventions (aka "signal functions") that the World Health Organization has recommended to reduce maternal and neonatal mortality (WHO, 2009). Basic EmONC interventions include administration of parenteral antibiotics, uterotonics, or anticonvulsants; manual removal of placenta; removal of retained products; assisted vaginal delivery; and basic neonatal resuscitation. Comprehensive care interventions include two additional services: ability to perform obstetric surgery (e.g., C- section) and blood transfusion. Facilities were classified based on whether they had, within the previous 3 months, performed each of these interventions. Because assisted vaginal delivery-using either forceps or vacuum extractor-is relatively uncommon in both Uganda and Zambia, some facilities were classified as fully providing EmONC care even if they did not perform assisted vaginal deliveries within the past 3 months (EmONC-1) Note 1: in Uganda, district and regional hospitals and health centers with surgical capacity (health centers IV) are designated as CEmONC facilities, able to perform each of the 9 signal functions and serving about 100,000 population [27]; in Zambia, only district and higher level hospitals are designated to provide CEmONC care [28]

Note 2: Unless otherwise noted, the figures in the table are numbers

examination of uterine rupture and abortion complications. In both countries, the number of maternal deaths in each facility was reconciled after crosschecking the reports of facility maternal deaths from communities.

\section{Rapid ascertainment process for institutional deaths (RAPID)}

Detection of maternal deaths in 16 CEmONC facilities in Uganda was enhanced using the RAPID methodology [35]. This method includes review of all health facility records related to deaths among women of reproductive age (WRA) to reduce undercounting of maternal deaths and improve their notification, reporting and review. RAPID data collection using pilot-tested extraction forms was conducted retrospectively at two points in time (November 2012 and July 2013) in all 16 facilities by CDC epidemiologists in collaboration with facility-based teams.

\section{Reproductive age (12-49 years) mortality studies (RAMOS)}

In Uganda, two retrospective RAMOS were conducted in the four SMGL districts to capture maternal deaths 
Table 3 Types of facility and community interventions, accomplishments, and resources added during SMGL Year 1

\begin{tabular}{|c|c|c|}
\hline & \multicolumn{2}{|c|}{ Gains during Year 1} \\
\hline & Uganda & Zambia \\
\hline \multicolumn{3}{|l|}{ Infrastructure developed } \\
\hline operating theaters built or renovated & 8 & 0 \\
\hline facilities with electricity upgrades & 35 & 22 \\
\hline facilities with uninterrupted water supply added & 6 & 10 \\
\hline mother shelters built or renovated & 4 & 11 \\
\hline \multicolumn{3}{|l|}{ Human Resources added } \\
\hline medical officers & 18 & 0 \\
\hline obstetricians & 0 & 0 \\
\hline clinical officers & 15 & 0 \\
\hline nurses & 20 & 0 \\
\hline midwives & 103 & 19 \\
\hline Health providers who received EmONC training & 316 & 199 \\
\hline \multicolumn{3}{|l|}{ Supply-chain system improvements } \\
\hline facilities that received EmONC equipment & 111 & 122 \\
\hline facilities that received essential commodities and supplies & 89 & 122 \\
\hline $\begin{array}{l}\text { facilities with protocols for clinical mgmt. of obstetric complications } \\
\text { complications }\end{array}$ & 57 & NA \\
\hline \multicolumn{3}{|l|}{ Communication-Transportation Added } \\
\hline vehicle ambulances & 7 & 5 \\
\hline motorcycle ambulances (E-rangers) & 16 & 14 \\
\hline bicycles & 1 & 46 \\
\hline \multicolumn{3}{|l|}{ Vouchers redeemed for institutional delivery ${ }^{a}$} \\
\hline transportation vouchers & 29,436 & NA \\
\hline private care vouchers (also cover transportation) & 85 & NA \\
\hline \multicolumn{3}{|l|}{ Community-based efforts added } \\
\hline community volunteers $^{\mathrm{b}}$ & 4076 & 1548 \\
\hline community mobilization events & 701 & 6 \\
\hline radio spots broadcast & 36,146 & 3807 \\
\hline
\end{tabular}

${ }^{a}$ Transportation vouchers introduced in 3 districts and private care vouchers in all 4 districts in Uganda; vouchers were not introduced in Zambia

${ }^{b}$ Includes village health teams (VHTs) — one per community in Uganda, trained to provide preventive MCH services and conduct surveillance activities_and Safe Motherhood Action Groups (SMAGs) in Zambia, recruited and trained to link communities with facility-based care

Note: All figures in the table are numbers

during the baseline (field work conducted in AugustSeptember 2012) and Year 1 (field work conducted in October-November 2013). The first step of each investigation, performed by village health teams (VHTs), consisted of identifying households in which a WRA had died. Trained VHTs compiled lists of deaths to WRA using their VHT registers. The second step consisted of a brief household investigation using a one-page screening tool to determine whether each WRA had been pregnant at the time of her death or in the 3 months preceding death. The third step consisted of interviewing the caretakers of women who died while pregnant or postpartum, using a special verbal autopsy (VA) questionnaire to explore causes and circumstances of maternal deaths $[31,36]$. The VA instrument developed in Uganda is a new and complex verbal and social autopsy questionnaire that has been featured in the 2013 WHO technical guidance on maternal death surveillance and response [36]. Each death was certified and coded independently by two physicians, with a third if consensus was not reached. Only maternal deaths during pregnancy, delivery and 42 days postpartum that occurred during baseline and Year 1 periods were retained in the analyses.

In Zambia, the SMGL districts did not have an existing community-based data collection mechanism analogous to the village health teams in Uganda and RAMOS was not conducted. 
Table 4 SMGL data sources by groups of indicators

\begin{tabular}{|c|c|c|c|c|c|}
\hline \multirow[t]{2}{*}{ Period and Indicator } & \multicolumn{3}{|l|}{ Uganda } & \multicolumn{2}{|l|}{ Zambia } \\
\hline & Community & $\begin{array}{l}\text { Health Center IV } \\
\text { and Hospitals }\end{array}$ & $\begin{array}{l}\text { Health Centers } \\
\text { III and II }\end{array}$ & Community & $\begin{array}{l}\text { Health Centers } \\
\text { and Hospitals }\end{array}$ \\
\hline \multicolumn{6}{|l|}{ Baseline (June 2011-May 2012) } \\
\hline $\begin{array}{l}\text { Routine and Emergency Obstetric } \\
\text { Care Indicators }\end{array}$ & NA & Facility Assessment & Facility Assessment & NA & Facility Assessment \\
\hline Institutional Deliveries & NA & $\begin{array}{l}\text { Individual Outcome } \\
\text { Data (POM) }\end{array}$ & $\begin{array}{l}\text { Enhanced Aggregate } \\
\text { Outcome Data }\end{array}$ & NA & $\begin{array}{l}\text { Enhanced Aggregate } \\
\text { Outcome Data }\end{array}$ \\
\hline AMTSL use & NA & $\begin{array}{l}\text { Individual Outcome } \\
\text { Data (POM) }\end{array}$ & $\begin{array}{l}\text { Enhanced Aggregate } \\
\text { Outcome Data }\end{array}$ & NA & NA \\
\hline $\begin{array}{l}\text { Direct Obstetric Complications } \\
\text { Prevalence Rates }\end{array}$ & NA & $\begin{array}{l}\text { Individual Outcome Data; Triangulation of } \\
\text { facility registers }\end{array}$ & $\begin{array}{l}\text { Enhanced Aggregate } \\
\text { Outcome Data }\end{array}$ & NA & $\begin{array}{l}\text { Enhanced Aggregate } \\
\text { Outcome Data }\end{array}$ \\
\hline $\begin{array}{l}\text { Case Specific Maternal Mortality } \\
\text { and Case Fatality Rates }\end{array}$ & RAMOS & RAPID & $\begin{array}{l}\text { Enhanced Aggregate } \\
\text { Outcome Data }\end{array}$ & $\begin{array}{l}\text { 4-distirct } \\
\text { Census }^{a}\end{array}$ & $\begin{array}{l}\text { Individual Maternal } \\
\text { Deaths }\end{array}$ \\
\hline Population Maternal Mortality & RAMOS & NA & NA & $\begin{array}{l}\text { 4-distirct } \\
\text { Census }^{\mathrm{a}}\end{array}$ & NA \\
\hline \multicolumn{6}{|l|}{ Year 1 (June 2012-May 2013) } \\
\hline $\begin{array}{l}\text { Routine and Emergency } \\
\text { Obstetric Care Indicators }\end{array}$ & NA & Facility Assessment & Facility Assessment & NA & Facility Assessment \\
\hline Institutional Deliveries & NA & $\begin{array}{l}\text { Individual Outcome } \\
\text { Data (POM) }\end{array}$ & $\begin{array}{l}\text { Enhanced Aggregate } \\
\text { Outcome Data }\end{array}$ & NA & $\begin{array}{l}\text { Enhanced Aggregate } \\
\text { Outcome Data }\end{array}$ \\
\hline AMTSL use & NA & $\begin{array}{l}\text { Individual Outcome } \\
\text { Data (POM) }\end{array}$ & $\begin{array}{l}\text { Enhanced Aggregate } \\
\text { Outcome Data }\end{array}$ & NA & NA \\
\hline $\begin{array}{l}\text { Direct Obstetric Complications } \\
\text { Prevalence Rates }\end{array}$ & NA & $\begin{array}{l}\text { Individual Outcome Data; Triangulation of } \\
\text { facility registers }\end{array}$ & $\begin{array}{l}\text { Enhanced Aggregate } \\
\text { Outcome Data }\end{array}$ & NA & $\begin{array}{l}\text { Enhanced Aggregate } \\
\text { Outcome Data }\end{array}$ \\
\hline $\begin{array}{l}\text { Case Specific Maternal Mortality } \\
\text { and Case Fatality Rates }\end{array}$ & RAMOS & RAPID & $\begin{array}{l}\text { Enhanced Aggregate } \\
\text { Outcome Data }\end{array}$ & $\begin{array}{l}\text { SMAG } \\
\text { Reporting }\end{array}$ & $\begin{array}{l}\text { Individual Maternal } \\
\text { Deaths }\end{array}$ \\
\hline Population Maternal Mortality & RAMOS & NA & NA & NA & NA \\
\hline
\end{tabular}

${ }^{a}$ Conducted in 2012; population maternal mortality rates were estimated at baseline but comparable data collection at the end of Year 1 was not conducted

${ }^{\mathrm{b}}$ Safe Motherhood Action Groups started to report community maternal deaths in 2013 but they cover less than a third of population of the 4 districts in Zambia

\section{Population denominators}

Calculation of population MMRs and selected process and outcome EmONC indicators (e.g. institutional delivery rate, $\mathrm{C}$-section rate, and met need for obstetric care) requires external population data. District-wide censuses were conducted with SMGL support in Zambia in 2012 and in Uganda in 2013 to enumerate households, population, and women of reproductive age. Enumerations were projected back to estimate 2011 population using the inverse growth coefficient derived from the intercensal population growth provided by the national statistics bureaus. Live births were estimated by applying crude birth rates - directly derived from 2010 national census in Zambia and calculated by summing expected births among WRA in each age group multiplied by the rural age specific fertility rates from 2011 DHS in Ugandato the baseline and Year 1 district populations.

The study protocol was reviewed by CDC's Institutional Review Board and approved by CDC Human Research Protection Office of the Center for Global Health; it complied with Uganda and Zambia Ministries of Health procedures for protecting human rights in research. For conducting verbal autopsies, written informed consent among the caretakers of the deceased subjects was obtained after informing them about the purpose and public health importance of the research, selection procedures, voluntary participation and confidentiality. Interviews were scheduled no sooner than 6-8 weeks after the death occurred.

\section{Statistical analyses}

The results shown here are based on 4-district data analyses performed for each country. They are based on the total population and total number of health facilities in the SMGL districts in each country. They are not a sample and are not representative of a larger population in the country.

Likewise the maternal mortality ratios presented are based on complete enumeration of all maternal deaths identified in facilities (Uganda and Zambia) and communities (Uganda) and thus not subject to sampling error, but may be affected by random variation and changes in case detection. In comparing the baseline and Year 1 periods, a z-statistic was used to calculate the $p$-value of the difference between the two MMRs, both in facilities and when comparing population MMRs [37]. Similarly, 
the changes in other core indicators, on the basis of complete counts of events during the two periods, were estimated using $\mathrm{z}$-statistics for significance testing. The McNemar's test, which is appropriate for dichotomous responses for matched pairs of data at different time points, was used to test for significance of changes between the baseline and Year 1 HFA indicators [38].

\section{Results}

Access to care, infrastructure, and delivery care improved in SMGL districts following implementation of the SMGL-supported interventions (Table 5). Almost all delivering facilities (95\%) in Uganda and Zambia provided delivery care $24 \mathrm{~h} / 7$ days per week by the end of Year 1 . The proportion of facilities with uninterrupted electricity and water supplies increased significantly in both countries. In Zambia, the proportion of facilities with functional communication systems doubled and those performing community outreach increased by $35 \%$. Availability of life-saving medications increased, with substantial reductions in facilities reporting stock-outs of magnesium sulfate and oxytocin in both countries. The practice of active management of the third stage of labor (AMTSL) increased significantly, becoming nearly universal (92-93\%) in both countries. The proportion of facilities conducting maternal death reviews (MDR), mandated by

Table 5 Selected facility characteristics and interventions at Baseline and Year 1 SMGL

\begin{tabular}{|c|c|c|c|c|c|c|c|c|}
\hline \multirow[t]{2}{*}{ Characteristic/Intervention } & \multicolumn{4}{|c|}{ Uganda (107 facilities) } & \multicolumn{4}{|c|}{ Zambia (113 facilities) } \\
\hline & Baseline $^{a}$ & Year $1^{\mathrm{a}}$ & $\%$ Change $^{\mathrm{b}}$ & Sig. Level & Baseline & Year 1 & $\%$ Change $^{b}$ & Sig. Level $^{\mathrm{c}}$ \\
\hline Availability 24/7 & 80.4 & 95.3 & 19 & $* * *$ & 68.1 & 94.7 & 40 & $* * *$ \\
\hline Community outreach activities (Zambia only) & NA & NA & NA & NA & 63.0 & 85.2 & 35 & $* * *$ \\
\hline Electricity available & 57.9 & 94.4 & 62 & $* * *$ & 56.6 & 76.1 & 33 & $* * *$ \\
\hline Water available & 76.6 & 94.4 & 22 & $* * *$ & 90.3 & 99.1 & 10 & $* * *$ \\
\hline Functional communications available ${ }^{d}$ & 93.5 & 92.5 & -1 & NS & 45.1 & 89.4 & 98 & $* * *$ \\
\hline Transportation available $5^{f}$ & 59.8 & 64.5 & 8 & NS & 54.9 & 61.1 & 11 & NS \\
\hline Sufficient number of beds & 35.5 & 73.8 & 108 & $* * *$ & 63.7 & 67.3 & 6 & NS \\
\hline Use of parenteral antibiotics in last 3 months & 85.0 & 92.5 & 9 & NS & 78.8 & 75.2 & -5 & NS \\
\hline Use of parenteral oxytocin in last 3 months & 70.1 & 95.3 & 36 & $* * *$ & 90.3 & 94.7 & 5 & NS \\
\hline Use of parenteral anticonvulsants in last 3 months & 49.5 & 37.4 & -24 & NS & 44.2 & 33.6 & -24 & NS \\
\hline Perform newborn resuscitation in last 3 months & 31.8 & 69.2 & 118 & $* * *$ & 26.5 & 63.7 & 140 & $* * *$ \\
\hline Perform manual removal of placenta in last 3 months & 26.2 & 48.6 & 85 & $* * *$ & 38.1 & 33.6 & -12 & NS \\
\hline Remove retained products in last 3 months & 18.7 & 50.2 & 168 & $* * *$ & 16.8 & 38.1 & 127 & *** \\
\hline Perform assisted vaginal delivery (AVD) in last 3 months & 4.7 & 11.2 & 138 & $* *$ & 9.7 & 14.2 & 46 & NS \\
\hline Perform surgery (C-section) (HC IV or higher) in last 3 months & 7.5 & 15.0 & 100 & $* * *$ & 4.4 & 4.4 & 0 & NS \\
\hline Perform blood transfusion (HC IV or higher) in last 3 months & 7.5 & 13.1 & 75 & ** & 5.3 & 6.2 & 17 & NS \\
\hline Breech delivery performed in last 3 months & 35.5 & 52.3 & 47 & ** & 36.3 & 51.3 & 41 & ** \\
\hline No stock out last 12 months: magnesium sulfate ${ }^{f}$ & 46.7 & 61.7 & 32 & $* *$ & 22.4 & 87.3 & 290 & $* * *$ \\
\hline No stock out last 12 months: oxytocin ${ }^{f}$ & 56.1 & 82.2 & 47 & $* * *$ & 78.2 & 97.5 & 25 & $* * *$ \\
\hline HIV rapid test kits currently available $\mathrm{f}^{\mathrm{f} g}$ & 71.0 & 82.2 & 16 & NS & 82.7 & 93.8 & 13 & ** \\
\hline Active management of 3rd stage of labor (AMTSL) & 75.7 & 92.5 & 22 & $* * *$ & 70.8 & 91.2 & 29 & $* * *$ \\
\hline Perform maternal death reviews & 6.5 & 33.6 & 417 & $* * *$ & 42.0 & 55.6 & 32 & NS \\
\hline Number of functioning CEmONC facilities & 7 & 16 & 129 & $* * *$ & 4 & 5 & 25 & $* * *$ \\
\hline Number of functioning BEmONC facilities & 3 & 9 & 200 & $* * *$ & 3 & 6 & 100 & *** \\
\hline Lower-level health facilities with partial BEmONC $\mathrm{C}^{\mathrm{h}}$ & 28 & 44 & 57 & $* * *$ & 24 & 37 & 54 & *** \\
\hline
\end{tabular}

a Baseline period is June 2011-May 2012; Year 1 period is June 2012-May 2013

${ }^{b}$ Percent change calculations based on unrounded numbers

c Asterisks indicate significance level of the difference between baseline and Year 1 outcomes for all facilities combined, using McNemar's exact test, as follows: *** $p<0.01,{ }^{* *} p<0.05$, NS not significant

dUganda: Facility owned landline, cell, two-way, or radio, or individual had cell phone. Zambia: Includes 2-way radio, landline, or cell phone with service eUganda: Available and functional motorized vehicle with fuel, funds for driver and maintenance generally available. Zambia: Includes motor vehicle, motorcycle, or bicycle

ZZambia: Kalomo facilities did not collect the information and were excluded from the analysis

${ }^{9}$ Uganda: Rapid HIV test was used in maternity ward in the last 3 months (does not indicated current availability)

hercent of health centers $(\mathrm{HC})$ that performed 4-5 basic emergency obstetric care interventions in the past 3 months

Note: Unless otherwise noted, the figures in the table are percentages of all facilities 
official policies in both countries, rose by over $400 \%$ in Uganda, but did not change significantly in Zambia. The number of EmONC facilities providing basic or comprehensive interventions rose by 200 and $129 \%$ respectively in Uganda and by 100 and 25\% in Zambia. The proportion of mid-level facilities performing 4-5
EmONC interventions increased by $57 \%$ in Uganda and by $54 \%$ in Zambia.

Virtually all outcome indicators that SMGL sought to improve changed substantially between baseline and Year 1 (Table 6). Most noteworthy are the sharp increases in facility delivery rates in SMGL districts in

Table 6 Pregnancy and maternal health outcomes in facilities at baseline and during Year $1 \mathrm{SMGL}$

\begin{tabular}{|c|c|c|c|c|}
\hline \multirow[t]{2}{*}{ Pregnancy and Maternal Health Outcomes } & \multicolumn{4}{|l|}{ Uganda } \\
\hline & Baseline & Year 1 & $\%$ Change & Significance $^{a}$ \\
\hline Number of live births - All facilities & 33,492 & 56,571 & 69 & $* * *$ \\
\hline Institutional delivery rate - All facilities (\%) & 45.5 & 73.8 & 62 & *** \\
\hline Institutional delivery rate - EmONC facilities (\%) & 28 & 36 & 28 & $* * *$ \\
\hline Number of obstetric complications treated ${ }^{b}$ & 5249 & 7696 & 47 & $* * *$ \\
\hline C-section rate as a proportion of all births (\%) & 5.3 & 6.5 & 23 & $* * *$ \\
\hline Met need for emergency obstetric care -All facilities (\%) & 46 & 66 & 42 & $* * *$ \\
\hline Met need for emergency obstetric care -EmONC facilities (\%) & 39 & 49 & 25 & $* * *$ \\
\hline Direct Obstetric Case Fatality Rate (\%) & 2.6 & 2.0 & -25 & $* * *$ \\
\hline Direct Maternal Mortality Ratio (MMR) & 416 & 269 & -35 & $* * *$ \\
\hline Facility MMR, overall & 534 & 345 & -35 & $* * *$ \\
\hline Obstetric hemorrhage $M M^{c}$ & 131 & 94 & -29 & $* * *$ \\
\hline Puerperal infection/Sepsis MMR & 75 & 32 & -57 & $* *$ \\
\hline Obstructed labor MMR ${ }^{d}$ & 72 & 30 & -58 & $* * *$ \\
\hline Abortion-related MMR ${ }^{e}$ & 63 & 35 & -44 & NS \\
\hline Pre-eclampsia/Eclampsia MMR & 45 & 46 & 3 & NS \\
\hline Other Direct Obstetric Causes MMR ${ }^{f}$ & 30 & 32 & 7 & NS \\
\hline \multirow[t]{2}{*}{ Indirect Obstetric Causes MMR } & 119 & 76 & -36 & NS \\
\hline & \multicolumn{4}{|l|}{ Zambia } \\
\hline Number of live births -All facilities & 21,914 & 30,619 & 40 & $* * *$ \\
\hline Institutional delivery rate (\%) & 62.6 & 84.3 & 35 & $* * *$ \\
\hline Institutional delivery rate-EmONC facilities (\%) & 26 & 30 & 17 & $* * *$ \\
\hline Number of obstetric complications treated ${ }^{b}$ & 1833 & 2462 & 34 & $* * *$ \\
\hline C-section rate as a proportion of all births (\%) & 2.7 & 3.1 & 15 & $* * *$ \\
\hline Met need for emergency obstetric care -All facilities (\%) & 34 & 45 & 31 & $* * *$ \\
\hline Met need for emergency obstetric care -EmONC facilities (\%) & 26 & 32 & 23 & *** \\
\hline Direct Obstetric Case Fatality Rate (\%) & 3.1 & 2.0 & -34 & $* *$ \\
\hline Direct Maternal Mortality Ratio (MMR) & 260 & 166 & -36 & $* *$ \\
\hline Facility MMR, overall & 310 & 202 & -35 & $* *$ \\
\hline Obstetric hemorrhage $M M^{c}$ & 110 & 72 & -34 & NS \\
\hline Obstructed labor MMR ${ }^{d}$ & 59 & 13 & -78 & $* *$ \\
\hline Other Direct Obstetric Causes MMR ${ }^{f}$ & 91 & 82 & -11 & NS \\
\hline Indirect Obstetric Causes MMR ${ }^{g}$ & 50 & 36 & -28 & NS \\
\hline
\end{tabular}

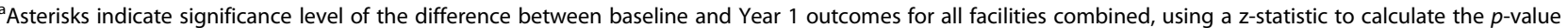
of the difference, as follows: ${ }^{* *} p<0.01,{ }^{* *} p<0.05$, NS not significant

${ }^{b}$ Excludes first-trimester complications (e.g. abortion-related complications and ectopic pregnancy)

Includes antepartum, intrapartum and postpartum hemorrhage

dObstructed and prolonged labor including rupture of the uterus

e Includes both induced and spontaneous abortions

Includes embolism, anesthetic-related deaths, and ectopic pregnancy

${ }^{9}$ Includes HIV-, TB- and malaria-related maternal deaths, and those due to other medical conditions 
both countries. In 1 year, the percentage of births that took place in health facilities rose by $62 \%$ (from 46 to 74\%) in Uganda and by 35\% (from 63 to 84\%) in Zambia. The EmONC delivery rates increased by 28 and $17 \%$, respectively. Cesarean section rates among all births in the SMGL districts increased by $23 \%$ in Uganda and 15\% in Zambia.

The number of complicated deliveries treated in facilities also increased in both countries. The overall proportion of expected obstetric complications treated (based on an assumed incidence of complications during pregnancy and childbirth of $15 \%$ ) increased by $42 \%$ in Uganda and by $31 \%$ in Zambia. The proportion of expected complications treated in EmONC facilities grew by $25 \%$ in Uganda and $23 \%$ in Zambia. The direct obstetric CFR declined by $25 \%$ in Uganda, and by $34 \%$ in Zambia.

Facility-based MMRs fell by 35\% in the SMGL districts in each country-from 534 to 345 deaths per 100,000 live births in Uganda and from 310 to 202 in Zambia. In Uganda, the facility MMR declined significantly between baseline and Year 1 for three major direct obstetric causes: obstetric hemorrhage (29\%); obstructed labor (58\%); and postpartum sepsis (57\%). In Zambia, only maternal mortality due to obstructed labor fell significantly (78\%).

Population-based maternal mortality in Uganda SMGL districts are based on information collected through verbal autopsies (Table 7). Only 6 suspected maternal deaths identified in the baseline RAMOS and 5 deaths in the Year 1 RAMOS were not followed by an interview due to household dissolution or relocation. There were no refusals to participate in the RAMOS studies. The number of maternal deaths dropped from 342 to 247 and MMR declined significantly in Year 1-from 452 deaths per 100,000 live births to 316 deaths, a reduction of $30 \%$. Significant declines in cause-specific mortality were observed for obstetric hemorrhage (43\%), obstructed labor (54\%), and sepsis (49\%). Mortality fell significantly during the intrapartum and up to $24 \mathrm{~h}$ post-partum period (27\%) and between 1 and 42 days after delivery (40\%). No significant change occurred in mortality before the onset of labor.

Substantial reductions were reported in the MMR in Uganda for all three major delays that can cause maternal death: mortality from delays in deciding to access appropriate care decreased by $46 \%$; from delays associated with reaching care fell by $61 \%$; and from delays in receiving quality care after reaching a facility declined by $43 \%$.

\section{Discussion}

A comprehensive health-system strengthening approach with improvements in access to, availability of, and quality of maternity care in the SMGL districts in the first

Table 7 Changes in district-wide Maternal Mortality Ratio (per 100,000 Live Births) by cause, timing of death, and the Three Delays: Uganda SMGL Districts

\begin{tabular}{|c|c|c|c|c|}
\hline & \multicolumn{2}{|c|}{ Maternal Mortality Ratio (MMR) } & \multirow[b]{2}{*}{$\%$ Change } & \multirow[b]{2}{*}{ Significance $^{a}$} \\
\hline & Baseline & Year 1 & & \\
\hline Total $^{b}$ & 452 & 316 & -30 & $* * *$ \\
\hline \multicolumn{5}{|l|}{ Causes of Death } \\
\hline Obstetric Hemorrhage & 128 & 73 & -43 & $* * *$ \\
\hline Pre-eclampsia/Eclampsia & 58 & 45 & -22 & NS \\
\hline Obstructed Labor (Including Uterine Rupture) & 71 & 33 & -53 & $* * *$ \\
\hline Puerperal infection/Sepsis & 33 & 17 & -48 & ** \\
\hline Abortion-related & 42 & 36 & -14 & NS \\
\hline Other Direct Obstetric Causes & 49 & 31 & -37 & NS \\
\hline Indirect Causes & 70 & 82 & 17 & NS \\
\hline \multicolumn{5}{|l|}{ Timing of Death } \\
\hline Antepartum & 62 & 60 & -3 & NS \\
\hline Intrapartum and Immediate Postpartum (up to 24 h) & 168 & 121 & -28 & ** \\
\hline$>24$ h-42 days Postpartum & 222 & 134 & -40 & $* * *$ \\
\hline \multicolumn{5}{|l|}{ The Three Delays } \\
\hline Delays in seeking care & 124 & 66 & -47 & *** \\
\hline Delays in reaching care & 40 & 16 & -60 & $* * *$ \\
\hline Delays in receiving care (one hour or more) & 92 & 54 & -41 & $* * *$ \\
\hline
\end{tabular}

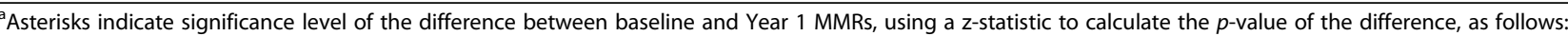
${ }^{* * *} p<0.01,{ }^{* *} p<0.05$, NS not significant

${ }^{\mathrm{b}}$ Baseline $\mathrm{MMR}=342$ maternal deaths/75,675 live births*100,000; Year $1 \mathrm{MMR}=247$ maternal deaths/78,261 live births *100,000 
year of the initiative was associated with a $30 \%$ decline in population-based maternal mortality in Uganda and a 35\% decline in MMR in Ugandan and Zambian health facilities. To our knowledge reductions in maternal mortality of this magnitude in such a short time are unprecedented in SSA. Improvements were also reported in nearly all indicators of maternal health.

Substantial increases in institutional delivery rates were an important contributing factor and are associated with encouraging communities to promote facility delivery (through community health workers and local leaders), improving transportation, preparing facilities for increased demand, and improving the quality of services $[29,30]$. The rate increased more in Uganda than in Zambia (62 vs. $35 \%$ ), suggesting the contribution of subsidized transport vouchers (introduced only in Uganda). However the Year 1 facility delivery rates in Zambia were higher (84\%) than in Uganda (63\%).

About $15 \%$ of women are estimated by WHO to develop pregnancy complications and require timely access to emergency obstetric care [14]. The number of fully functional EmONC facilities providing such care and the EmONC delivery rate rose significantly in both countries, an indication of increased capacity to better respond to obstetric emergencies. As more women with direct obstetric complications accessed EmONC, the met need for emergency obstetric care increased. The increase in met need documented here (42\% in Uganda and $31 \%$ in Zambia) is a conservative estimate because it did not take into account first trimester complications treated in facilities (including post-abortion complications, whose severity could often not be determined); nor did it take into account treatment of complications developed several days after delivery (e.g. postpartum sepsis) that were admitted directly to the postpartum ward. Care for these complications increased during Year 1 due to better access and referral pathways [29].

The EmONC improvements enhanced capacity for surgical obstetric care. Each country reported a significant increase in the population C-section rate. However only Uganda's Year 1 rate of $6.5 \%$ was within the $5-15 \%$ range recommended by WHO. It should be noted that although the $\mathrm{C}$-section rate increased, information is not available to examine how appropriate the decision for this route of delivery was and if any alternative management attempts were made (e.g. expected management, AVD, manual rotation of the occiput). Further special studies would be necessary to evaluate the quality of $\mathrm{C}$ section deliveries in SMGL districts.

Availability of emergency obstetric care within $2 \mathrm{~h}$ of the onset of a complication, improved management and supply chains, routine use of AMTSL, and rising Csection rates are indications of improved quality of obstetric care [14]. These improvements led to declines in the CFRs for direct obstetric complications treated in facilities, though they still exceeded the WHO recommended level of $<1 \%$. The CFRs reported here are conservative estimates because first trimester complications were not included in the CFR denominators while deaths that occurred following these complications were captured in the numerators.

Obstetric hemorrhage declined significantly in Uganda, in facilities and the population as a whole, likely associated with the increase in use of AMTSL, manual removal of placenta, removal of retained products and availability of blood transfusions and obstetric surgery. Nevertheless, it remained the leading cause of maternal death in both countries. In Uganda, obstructed labor (including uterine rupture) and sepsis (often due to prolonged labor) showed the sharpest declines in both facilities and in the population, likely due to the increased availability of C-sections. All other causes of death did not change significantly. The causes of death identified in this analysis are similar to WHO cause-of-death estimates, but differ from the Global Burden of Disease (GBD) estimates, which identify induced abortion as the greatest single contributor to maternal mortality in Eastern SSA [5, 11, 39].

The 30\% decline in population-based maternal mortality in Uganda provides the most credible evidence of the success of the SMGL initiative in Year 1. Declines in mortality were significant during delivery and immediately postpartum (28\%), when SMGL interventions would be expected to have their greatest impact. The largest decline occurred in mortality from $25 \mathrm{~h}$ to 42 days postpartum $(40 \%)$ and was likely rooted in a better management of women during labor and delivery, which prevents complications that extend longer post-partum such as sepsis. A shift in the place of death (from $48 \%$ of maternal deaths occurring in facilities at baseline to $63 \%$ in Year 1) [31] is evidence that more women with severe complications are reaching health facilities, some accessing care many hours after complicated home deliveries and possibly not getting there soon enough while others receiving lifesaving postpartum care. The timing of death in relationship to labor and delivery is similar to the 2013 GBD reports, which estimate that $26 \%$ of maternal deaths worldwide occur intrapartum and immediately postpartum and $49 \%$ during $25 \mathrm{~h}$ to 42 days after delivery.

Although facility-based MMR data can be used to improve health planning and quality of care, this information should not be viewed as representative of the districts as a whole. Facility-based MMRs may be higher or lower than those reported in the general population depending on the mix of patients (with more or fewer severe complications), the timeliness of medical care, the quality of the care, the proportion of deliveries at facilities, and the length of stay post-delivery. Facilitybased MMRs are also subject to selection bias because 
they include only women who accessed obstetric care services.

Declines in the CFR contributed to the reductions in MMRs. CFR is largely used as a proxy outcome indicator to signal changes in quality of care in EmONC services [14]. This decline shows that life-saving emergency obstetric care provided for complicated deliveries was effective and the quality of care improved despite a large increase in the volume of patients attended and the number of complicated deliveries.

The examination of MMR using a "Three-Delay" framework can help identify the relative contribution of health care decision-making, accessing care, and quality of childbirth services to the elimination of preventable maternal deaths. SMGL interventions were associated with substantial reductions in MMRs for all three of the major delays, suggesting that comprehensive community and facility approaches are needed for significant maternal mortality reductions to occur.

In settings with limited registration of births and deaths and incipient health information systems, monitoring of maternal mortality is largely done through model-based estimates [11, 39]. Country-owned, real-time, district level direct measurements of maternal mortality in Uganda and Zambia were made possible, for the first time, through the SMGL initiative. This assessment employed multiple methods to detect changes in maternal mortality in communities and facilities. It provided information about the processes and outputs that mediated maternal death declines and triggered countries' decisions to support scale-up of the SMGL approach.

This evaluation compares intervention districts before and after SMGL implementation, without a control in non-intervention districts. SMGL was rapidly launched as a full-coverage initiative, so an appropriate control group within the pilot districts could not have been established. Each country implemented district-level interventions with similar scope, timelines and intensity and adopted identical monitoring and evaluation indicators. However, interventions were prioritized and implemented differently, reflecting existing country contexts and needs. For example, Zambia did not have a community-based system to collect health data in place before the SMGL initiative began. It set up a new system of community key informants (Safe Motherhood Action Groups or SMAGs), tasked to track each pregnant woman until the end of the 42-day postpartum period, but logistic challenges limited the coverage. Similarly, data availability and quality in health facilities varied between and within each country. Although the absence of control districts introduced inherent limitations in our ability to attribute positive health outcomes to the SMGL interventions, significant improvements did occur in most outcomes in SMGL districts in both countries, despite differences in the measurement approaches.

The comparison highlights accomplishments, particularly maternal mortality declines, likely associated with the introduction of the SMGL model. The recently estimated overall decline in Uganda has been about 3\% per year [4], making it extremely unlikely that the 30\% reduction in Uganda's SMGL districts was unrelated to the SMGL interventions.

The observed decline in MMRs in this analysis is conservative. Since SMGL's investments started before the official launch in June 2012, the baseline period actually includes several months of building up to the fullfledged model, meaning that the documented decline in MMR is in all likelihood an underestimate. Furthermore, the completeness of mortality data depends on the accuracy of causes of death determination. Improvements in data accuracy mediated by SMGL rendered the baseline results not entirely comparable with the Year 1 results. Several factors, including lack of information about the antenatal period, lack of 24/7 laboratory diagnostics, limited experience with classification and coding of deaths, and low utilization of MDRs prior to Year 1 may have contributed to a greater extent to underreporting of maternal deaths at baseline than in Year 1, resulting in a smaller observed decline in MMR. Retrospective data collection on pregnancy and mortality outcomes in facilities and in communities does not allow for a detailed evaluation of the quality of care received. In the absence of patient records, case management details on complicated deliveries, discharge notes, or direct observation of practices, information from registers lack details about prenatal period, the time between admission and delivery, if complications were present at admission, for how long, and how severe they were, whether a complete and timely assessment of the status at admission was performed, and what was the quality of monitoring and care during labor and delivery. Smaller scale quality of care studies in a subset of SMGLsupported facilities are proposed to help document quality of care and remaining gaps.

\section{Conclusions}

Maternal mortality fell significantly in 1 year in eight pilot districts in Uganda and Zambia following the introduction of the SMGL model. This decline is likely due to parallel improvements of the supply- and demand-side for obstetric and HIV services coupled with improved quality of care at facilities and improved coordination and health management throughout the districts. Although implementation and emphasis of SMGL interventions were not identical in each district, maternal health outcomes in facilities improved in both countries. 
In Uganda, the $30 \%$ population-based decline in maternal mortality was accomplished through a comprehensive district system strengthening approach that led to reductions in the "Three Delays." Maternal mortality reductions in these countries of such a magnitude in 1 year show that it is possible to greatly accelerate progress in saving mothers' lives. The lessons learned from SMGL can inform policymakers and program managers in other low and middle income settings where similar approaches could be utilized to rapidly reduce maternal mortality.

\begin{abstract}
Abbreviations
AMTSL: Active management of the third stage of labor; AVD: Assisted vaginal delivery; BEmONC: Basic emergency obstetric and newborn care; CDC: Centers for Disease Control and Prevention; CEmONC: Comprehensive emergency obstetric and newborn care; CFR: Case fatality rate (for direct obstetric complications receiving care); C-section: Cesarean section; DHS: Demographic Health Survey; EmONC: Emergency obstetric and newborn care; GBD: Global burden of disease; HFA: Health facility assessment; HIV: Human immunodeficiency virus; ICD: International Statistical Classification of Diseases and Related Health Problems; M\&E: Monitoring and evaluation; MDG: Millennium development goal; MDR: Maternal death review; MMR: Maternal mortality ratio; NMR: Neonatal mortality rate (in health facilities, pre-discharge); PMR: Perinatal mortality rate (in health facilities, pre-discharge); RAMOS: Reproductive age mortality study; RAPID: Rapid ascertainment process for institutional deaths; SMAG: Safe motherhood action group; SMGL: Saving mothers, giving life; SSA: subSaharan Africa; VA: Verbal autopsy; VHT: Village health team; WHO: World Health Organization; WRA: Women of reproductive age (15-49 years)
\end{abstract}

\section{Acknowledgements}

Thousands of individuals participated in activities to monitor and evaluate Phase 1 of the Saving Mothers, Giving Life (SMGL) initiative. We would like to thank the leadership and the M\&E experts of the country implementation partners-Baylor Children's Foundation, Infectious Diseases Institute in Uganda and Center for Infectious Disease Research, Center for Applied Health Research and Development (Boston University), and Maternal and Child Health Integrated Program in Zambia_ for overseeing and carrying out the components of the monitoring and evaluation. Our special thanks go to Makerere University School of Public Health in Uganda, Zambia Central Statistics Office, and University of Zambia for their contributions to selected data collection activities. We are grateful to the Governments of Uganda and Zambia, their Ministries of Health, the District Health Offices, the parish supervisors and interviewers, and the village health teams (in Uganda) and community safe motherhood action groups (in Zambia). This work would not have been possible without the continuous support of the CDC and USAID country offices. Note: The SMGL research group during Phase 1 was composed of selected staff affiliated with country SMGL implementation teams, CDC and USAID country offices, and the monitoring and evaluation technical team of the CDC Atlanta and USAID Washington DC.

\section{Funding}

Phase 1 SMGL implementation was primarily funded by CDC, Atlanta, Georgia (Cooperative agreements GPS003057 and GPS002918) and USAID, Washington, D.C. The funding agencies had no influence or control over the content of this article, which is the responsibility of the authors. Views represented in this manuscript are those of the authors and do not represent those of the US Government.

\section{Availability of data and materials}

All data that support the findings of this study are archived in the libraries of the CDC country offices. Restrictions may apply to the availability of some of these data, and so are not publically available. Data are however available for authors upon reasonable request and with permissions of the Governments of Uganda and Zambia. Requests for permission to access data are evaluated to ensure these data are appropriate for the use sought, will be used consistent with any applicable legal restrictions on the data, and will be used for an appropriate purpose.

\section{Authors' contributions}

FS coordinated the research and did the analyses, with help from ID, PS, TW, LM, WO and JM. FS, HG and ID wrote the initial manuscript; CMC contributed to the revision. JA and EC represented the Ugandan and Zambian Ministries of Health in deciding on the design, data acquisition, and data interpretation and in leading country disseminations; they provided critical feedback in interpreting the results. The SMGL research group including the first author participated in design, data collection, and coordination. All authors had full access to all data in the study. FS had final responsibility to submit for publication. All authors read and approved the final manuscript.

\section{Competing interests}

The authors declare that they have no competing interests.

\section{Consent for publication}

The ethics committees did not require for the project to seek consent for publication from individual participants. Most data were obtained from routine facility registers without individual patient identifiers. For verbal autopsies, written informed consent was obtained from an identified individual in each household, who provided the information voluntarily, was informed about confidentiality of the study, and approved the use of information for improving public health and clinical practices. Individuals who were interviewed for verbal autopsies consented in writing and were informed that their responses will be kept confidential and individual information provided will be aggregated so that they and their deceased relatives cannot be identified. No data sets created included individual identifiers. The manuscript does not include details, images, or videos relating to individual participants.

\section{Ethics approval and consent to participate}

The study protocol was reviewed and approved by recognized ethics committees in each country and complied with Uganda and Zambia Ministries of Health procedures for protecting human subjects. Specifically, the following ethics organizations approved the study. In Uganda, ethical clearance was given by the Mekerere University School of Public Health Higher Degrees, Research and Ethics Committee (HDREC), approval \#156 of January 19, 2012, and the Uganda National Council for Science and Technology (UNCST), approval number 2927 of August 23, 2012. In Zambia, ethical clearance was given by the University of Zambia (UNZA) Biomedical Research Ethics Committee UNZA (approval \# 018-03-12 of May 22, 2012) and the Permanent Secretary of the Ministry of Health (MH/101/176 of August 27, 2012). Saving Mothers Giving Life initiative has been reviewed by the local review boards under protocol names that were specific to each country. Local ethical approvals were obtained prior to the CDC's ethical review. The CDC Center for Global Health Human Subject Review Board approved the study and determined that CDC activities included in the SMGL monitoring and evaluation do not constitute "human subject research," since they do not interfere or interact with living individuals for research purposes and do not obtain individually identifiable private information. For conducting verbal autopsies, written informed consents from the caretakers of the deceased subjects were obtained after informing them about the purpose and public health importance of the study, selection procedures, voluntary participation and confidentiality. Written consent was also obtained from facility in-charge or directors prior to collecting routine health facility data in both countries.

\section{Author details}

'Division of Reproductive Health, Centers for Disease Control and Prevention, 4770 Buford Hwy, Atlanta, GA 30341, USA. ${ }^{2}$ Uganda Country Office, Centers for Disease Control and Prevention, Plot 51-59 Nakiwogo Road, Entebbe, Uganda. ${ }^{3}$ Ministry of Health, Zambia Country Office, Centers for Disease Control and Prevention, 351 Independence Avenue, Lusaka, Zambia10101. ${ }^{4}$ Uganda Ministry of Health, 6 Lourdel Road, Wandegeya, Kampala, Uganda. ${ }^{5}$ Zambia Ministry of Health, Ndeke House, Haile Selassie Avenue, Lusaka, Zambia. ${ }^{6}$ United States Agency for International Development, 2100 Crystal Drive, Arlington, VA 22202, USA. ' Saving Mothers Giving Life Research Group, Atlanta, USA. ${ }^{8}$ Field Support Branch, Division of Reproductive Health, 
National Center for Chronic Disease Prevention and Health Promotion, Centers for Disease Control and Prevention, 4770 Buford Hwy, NE, MS F74, Atlanta, GA 30341, USA.

Received: 13 September 2015 Accepted: 9 January 2017

Published online: 19 January 2017

\section{References}

1. WHO, UNICEF. Countdown to 2015. Accountability for maternal, newborn and child survival: the 2013 update. Geneva: World Health Organization; 2013. p. 109. Available from: http://countdown2015mnch.org/documents/ 2013Report/Countdown_2013-Update_withprofiles.pdf.

2. Campaign on accelerated reduction of maternal, newborn and child mortality in Africa [CARMMA]. Addis Ababa: African Union Commission; 2009 May. Available from: http://www.carmma.org/. Accessed 13 Aug 2014.

3. Ki-moon B. Global strategy for women's and children's health. New York: United Nations; 2010 Sept. 20 p. Available from: http://www.un.org/en/ mdg/summit2010/pdf/Global\%20Strategy.pdf.

4. WHO, UNICEF, UNFPA, World Bank, United Nations. Trends in maternal mortality: 1990 to 2013. Estimates by WHO, UNICEF, UNFPA, the World Bank, and the United Nations Population Division. Geneva: World Health Organization; 2014. p. 68. Available from: http://apps.who.int/iris/bitstream/ 10665/112682/2/9789241507226_eng.pdf?ua=1.

5. WHO. World Health Statistics 2014. Geneva: World Health Organization: 2014. p. 180. Available from: http://apps.who.int/iris/bitstream/10665/ 112738/1/9789240692671 eng.pdf?ua=1. Accessed 13 Aug 2014.

6. WHO. Choosing Interventions that are Cost-Effective (WHO-CHOICE): country specific unit costs. Geneva: World Health Organization; 2014 Available from: http://www.who.int/choice/country/country_specific/en/ index.html. Accessed 10 Aug 2014.

7. Bustreo F, Say L, Koblinsky M, Pullum TW, Temmerman M, Pablos-Mendez A. Ending preventable maternal deaths: the time is now. Lancet Glob Health. 2013:1(4):e176-7.

8. Requejo JH, Brice J, Barros AJD, et al. Countdown to 2015 and beyond: fulfilling the health agenda for women and children. Lancet. 2015;385(9966): 466-76. doi:10.1016/S0140-6736(14)60925-9. Epub 2014 Jun 29.

9. Bhutta ZA, Ahmed T, Black RE, et al. Maternal and Child Undernutrition Study Group. What works? Interventions for maternal and child undernutrition and survival. Lancet. 2008;371(9610):417-40.

10. Bhutta ZA, Das JK, Bahl R, et al. for The Lancet Newborn Interventions Review Group and The Lancet Every Newborn Study Group. Can available interventions end preventable deaths in mothers, newborn babies, and stillbirths, and at what cost? Lancet. 2014;384:347-70

11. Say L, Chou D, Gemmill A, Tunçalp O, et al. Global causes of maternal death: a WHO systematic analysis. Lancet Glob Health. 2014;2(6):e323-33. doi:10.1016/S2214-109X(14)70227-X. Epub 2014 May 5.

12. US President's Emergency Plan for AIDS Relief (PEPFAR). The power of partnerships: the president's emergency plan for AIDS relief: third annual report to congress. Washington DC: Office of the US Global AIDS Coordinator, US Department of State; 2007.

13. U.S. Global Health Initiative (GHI). Promoting partnerships to advance $\mathrm{GHI}$ objectives. Washington DC; 2013.

14. WHO, UNFPA, UNICEF, Averting Maternal Death and Disability Program. Monitoring emergency obstetric care: a handbook. Geneva: World Health Organization; 2009. http://www.who.int/reproductivehealth/publications/ monitoring/9789241547734/en/index.html. Accessed 12 Mar 2014.

15. Thaddeus S, Maine D. Too far to walk: maternal mortality in context. Soc Sci Med. 1994;38(8):1091-110.

16. Fournier P, Dumont A, Tourigny C, Dunkley G, Drame S. Improved access to comprehensive emergency obstetric care and its effect on institutional maternal mortality in rural Mali. Bull World Health Organ. 2009;87(1):30-8

17. Paxton A, Maine D, Freedman L, Fry D, Lobis S. The evidence for emergency obstetric care. Int J Gynaecol Obstet. 2005:88(2):181-93.

18. Hu D, Bertozzi S, Gakidou E, Sweet S, Goldie S. The Costs, Benefits, and CostEffectiveness of Interventions to Reduce Maternal Morbidity and Mortality in Mexico. PLoS One. 2007;2(8):e750

19. Souza JP, Gulmezoglu AM, Vogel J, et al. Moving beyond essential interventions for reduction of maternal mortality (the WHO Multicountry Survey on Maternal and Newborn Health): a cross-sectional study. Lancet. 2013;381:1747-55
20. World Health Organization (WHO), Department of Reproductive Health and Research. WHO recommendations for the prevention and treatment of postpartum haemorrhage. Geneva: World Health Organization; 2012. p. 41. Available from: http://www.who.int/reproductivehealth/publications/ maternal_perinatal_health/9789241548502/en/index.html. Accessed 28 July 2014.

21. lyengar K, lyengar SD, Suhalka V, Dashora K. Pregnancy-related deaths in rural Rajasthan, India: exploring causes, context, and careseeking through verbal autopsy. J Health Popul Nutr. 2009;27(2): 293-302.

22. Lawn JE, Blencowe H, Oza S, et al. for The Lancet Every Newborn Study Group. Progress, priorities, and potential beyond survival. Lancet. 2014;384: 189-205.

23. Abouchadi S, Belghiti Alaoui A, Meski FZ, De Brouwere V. Implementing a maternal mortality surveillance system in Morocco - challenges and opportunities. Trop Med Int Health. 2013;18(3):357-65.

24. Gupta SD, Khanna A, Gupta R, Sharma NK, Sharma ND. Maternal mortality ratio and predictors of maternal deaths in selected desert districts in Rajasthan a community-based survey and case control study. Women Health Issues. 2010;20(1):80-5.

25. Oye-Adeniran BA, Odeyemi KA, Gbadegesin A, Ekanem EE, Osilaja OK, Akin-Adenekan O, Umoh AV. The use of the sisterhood method for estimating maternal mortality ratio in Lagos state, Nigeria. J Obstet Gynaecol. 2011;31(4):315-9.

26. Ronsmans C, Graham WJ, and the Lancet Maternal Survival Series steering group. Maternal mortality: who, when, where, and why. Lancet. 2006;368:1189-2000.

27. Government of Uganda, Ministry of Health. Health Sector Strategic and Investment Plan (HSSIP): promoting people's health to enhance socioeconomic development 2010/11-2014/15. Kampala, Uganda; 2010

28. Government of Zambia, Ministry of Health. National Health Strategic Plan (NHSP) 2011-2015: towards attainment of the millennium development goals and national health priorities in a clean, caring and competent environment. Lusaka, Zambia; 2010.

29. Centers for Disease Control and Prevention (CDC). Saving mothers, giving life: emergency obstetric and newborn care access and availability phase 1 monitoring and evaluation report. Atlanta: Centers for Disease Control and Prevention, US Department of Health and Human Services; 2014. Available from: https://www.cdc.gov/reproductivehealth/global/ publications/pdfs/smgl-emergencyobstetriccare-508.pdf. Accessed 13 Aug 2015

30. Kruk ME, Galea S, Grepin KA, et al. External Evaluation of Saving Mothers, Giving Life: Final Report. New York: Columbia University; 2013.

31. Centers for Disease Control and Prevention (CDC). Saving mothers, giving life: maternal mortality. Phase 1 monitoring and evaluation report. Atlanta: Centers for Disease Control and Prevention, US Dept. of Health and Human Services; 2014. Available from: https://www.cdc.gov/reproductivehealth/ global/publications/pdfs/smgl_mortality_508tagged.pdf. Accessed 13 Aug 2015.

32. World Health Organization. The WHO Application of ICD-10 to Deaths during Pregnancy, Childbirth and the Puerperium: ICD-MM. Geneva: World Health Organization; 2012.

33. Averting Maternal Death and Disability Program. Needs assessment of emergency obstetric and newborn care: data collection modules. New York: Averting Maternal Death and Disability Program, Columbia University; 2010.

34. CDC. Saving mothers, giving life: maternal and perinatal outcomes in health facilities phase 1 monitoring and evaluation report. Atlanta: Centers for Disease Control and Prevention, US Dept. of Health and Human Services; 2014. Available from: https://www.cdc.gov/reproductivehealth/global/ publications/pdfs/maternalandperinataloutcomes.pdf. Accessed 13 Aug 2015

35. Immpact. Rapid ascertainment process for institutional deaths (RAPID). Module 4, Tool 2. In: Immpact Toolkit: A Guide and Tools for Maternal Mortality Program Assessment. Aberdeen: University of Aberdeen; 2007.

36. World Health Organization. Maternal death surveillance and response: technical guidance information for action to prevent maternal death. Geneva: World Health Organization; 2013. http://apps.who.int/iris/bitstream/ 10665/87340/1/9789241506083_eng.

37. Hoyert DL. Maternal mortality and related concepts. Vital Health Stat 3. 2007:(33):1-13. 
38. Suchower $L$ and Copenhaver M. Using the SAS System to perform McNemar's test and calculate the kappa statistic for matched pairs of data. North East SAS Users Group (NESUG) Proceedings. Boston Massachustes; 1996. http://www.lexjansen.com/nesug/nesug96/ NESUG96112.pdf. Accessed 28 Jun 2014.

39. Kassebaum N, Bertozzi-Villa A, Coggeshall M, et al. Global, regional, and national levels and causes of maternal mortality during 1990-2013: a systematic analysis for the Global Burden of Disease Study 2013. Lancet. 2014;384(9947):980-1004. doi:10.1016/S0140-6736(14)60696-6. Epub 2014 May 2.

Submit your next manuscript to BioMed Central and we will help you at every step:

- We accept pre-submission inquiries

- Our selector tool helps you to find the most relevant journal

- We provide round the clock customer support

- Convenient online submission

- Thorough peer review

- Inclusion in PubMed and all major indexing services

- Maximum visibility for your research

Submit your manuscript at www.biomedcentral.com/submit 